\title{
Produção e consumo de cerveja artesanal como alternativa para hotéis fazenda
}

\section{Production and consumption of craft beer as an alternative to farm hotels}

\author{
Sérgio Domingos de Oliveira ${ }^{1}$ \\ Lélio Galdino Rosa ${ }^{2}$ \\ Mariana Tomazin ${ }^{3}$
}

\begin{abstract}
RESUMO - A produção de cervejas artesanais no Brasil está em expansão nos últimos anos. Por isso, buscou-se com essa pesquisa aproximar esse tema ao contexto dos hotéis fazenda. Para tal, utilizou-se o método dedutivo, por meio de uma abordagem qualitativa e exploratória, estruturada com levantamento bibliográfico. Dessa forma, a pesquisa apresenta como a produção de cervejas artesanais pode ser uma alternativa vinculada a diversos produtos e experiências nesse tipo de meio de hospedagem. $\mathrm{O}$ estudo identifico $\mathrm{u}$ como possibilidades resultantes da produção artesanal de cervejas em hotéis fazenda: o valor agregado ao cardápio, a complementação de serviços, a promoção de eventos, a estruturação de roteiros e visitas guiadas, a oferta de cursos específicos, além da possibilidade de consumir um produto único e local. Esses atributos podem beneficiar tanto a dinâmica do empreendimento quanto do destino e região.
\end{abstract}

Palavras-chave: Produto Turístico. Ruralidade. Hotel Fazenda. Cerveja Artesanal. Serviços.

\footnotetext{
${ }^{1}$ Doutorado em Engenharia de Produção e Sistemas pela Universidade Federal de Santa Catarina (UFSC). Mestrado em Engenharia de Produção e Sistemas pela UFSC. Graduação em Turismo e Hotelaria pela Universidade do Vale do Itajaí (UNIVALI). Professor Adjunto da Universidade Federal Rural do Rio de Janeiro (UFRRJ). E-mail: sedoliveira@gmail.com

2 Doutorado em Geografia pela Universidade Estadual Paulis ta (UNESP - Rio Claro). Mestrado em Turismo e Hotelaria pela Universidade do Vale do Itajaí (UNIVALI). Especialização em Administração Hoteleira pelo SENAC-Minas Gerais. Graduação em Tecnologia em Hotelaria pela Universidade Anhembi Morumbi. Graduação em Ciências Econômicas pelas Faculdades Integradas do Triangulo Mineiro. Profes sor As sociado do Curso Superior em Tecnologia em Hotelaria da Universidade Federal Fluminense (UFF). E-mail: leliogaldino@gmail.com

${ }^{3}$ Mestrado em Turismo pela Universidade de Brasília (UnB). Graduação em Turismo pela Universidade Estadual Paulista (UNESP). Doutoranda em Turismo pela Universidade de São Paulo (USP). Pesquisadora e bolsista da Coordenação de Aperfeiçoamento de Pessoal de Nível Superior (CAPES). E-mail: mariana_tomazin@hotmail.com
} 
ABSTRACT -The production of craft beers in Brazil is expanding in the recent years. Therefore, this research sought to bring this theme closer to the context of the farm hotels. For this, the deductive method was used, through a qualitative and exploratory approach, structured with bibliographic survey. Thus, the research presents how the production of craft beers can become an alternative linked to several products and experiences in this type of accommodation. The article identifies as possible results from the artisanal production of beers in farm hotels: the value added to the menu, the complementation of the services, the promotion of events, the new itineraries and guided tours, the offering of specific courses, besides the possibility of consuming a unique and local product. These attributes can benefit both the dynamics of the place and the destination and region.

Keywords: Tourism Products. Rurality. Farm Hotel. Craft Beer. Services. 


\section{INTRODUÇÃO}

A produção de cervejas artesanais apresenta um crescimento tanto no Brasil quanto no mundo. Em 2018 quase 10\% dos municípios brasileiros já possuíam pelo menos uma cervejaria e, em junho de 2019, o Ministério de Agricultura, Pecuária e Abastecimento (MAPA) registrou a instalação da milésima cervejaria no Brasil (BRASIL, 2019). Esta expansão está atrelada ao avanço de novas tecnologias e facilidades para a fabricação da cerveja. Essa estrutura de produção pode ser implementada em diferentes empreendimentos, valorizando sua marca e agregando serviços e produtos. Dentro da lógica que tange a competitividade turística, o aumento da oferta de cervejas artesanais indica que há uma demanda em potencial que merece atenção.

Assim, propõem-se nesse artigo pensar a produção de cervejas artesanais como uma alternativa vinculada aos produtos e experiências de hotéis fazenda. Oferecer serviços diferenciados, personalizados e competitivos aos seus hóspedes é fundamental e é neste contexto que a produção de cervejas artesanais pode agregar valor às atividades já existentes, que são, geralmente, relacionadas à oferta gastronômica.

Desta forma, a produção das cervejas artesanais pode gerar, além do oferecimento de produtos personalizados, atividades complementares, como visitas guiadas ou cursos de curta duração para a produção da cerveja, ampliando as atividades de lazer dos seus hóspedes, os quais já são beneficiados pela paisagem e vivências no campo. Afinal, seu processo de produção se desenvolve em diversas etapas, ou seja, necessita de um ciclo de vários dias até que a cerveja esteja pronta para o consumo. Além disso, estas atividades podem gerar novos empregos, contribuindo para a economia da região e, consequentemente, para o meio de hospedagem.

Para a realização da pesquisa adotou-se o método dedutivo, pois a construção permeou uma cadeia de raciocínio, de análise do geral para o particular, chegando-se a uma conclusão, sendo a abordagem da pesquisa qualitativa (SILVA; MENEZES, 2001). A pesquisa, de nível exploratório, foi estruturada com o propósito de vislumbrar maior familiaridade com o problema, com vistas a torná-lo explícito, envolvendo, prioritariamente, o levantamento bibliográfico, associada à observação assistemática, mediante o uso de dados obtidos pela experiência com o tema, ou seja, a expressão de sua 
realidade ao longo da redação do artigo, conforme a necessidade (SILVA; MENEZES, 2001).

Destaca-se que as iniciativas aqui refletidas podem dialogar com a atratividade, não apenas dos hotéis fazenda, mas fortalecer os destinos, pois suas características e a identidade local podem estar expressas no fortalecimento desse produto turístico mile nar e no encadeamento dos demais serviços atrelados.

Nesse sentido, promove-se nas seções seguintes desse artigo uma discussão sobre a cultura cervejeira no mundo e sua relação com a hospitalidade e o turismo, por meio de práticas e espaços de hospitalidade, especialmente em hotéis fazendas, verificando, assim, a possibilidade de que a cerveja passe a figurar como elemento de atração e de customização de seus negócios, correlacionando-a com a cultura rural local.

\section{A CERVEJA E SUA TRAJETÓRIA NA HISTÓRIA}

A produção cervejeira tem registros de suas origens 9.000 anos a.C., registros até mesmo anteriores aos da produção de vinho, segundo Beltramelli (2014). Morado (2017), por sua vez, observou em seu histórico sobre a cerveja a existência de registros indicando que ela foi descoberta em 3400 a.C., antes mesmo da invenção da roda, registrada apenas em 3000 a.C.

Assim, ainda que de forma rudimentar, essa bebida marca uma era na história da civilização, correlacionada à produção doméstica de cereais pelos Orientais Próximos. Com o tempo, a cerveja encontrou o caminho para a Gália, através do Egito e do Império Romano, e como a produção de cerveja era, inicialmente, uma tarefa doméstica, as primeiras cervejeiras eram mulheres (FLANDERS, 2019). Na Idade Média, aind a segundo Flanders (2019), os mosteiros se tornaram centros de conhecimento sobre agricultura, pecuária e trabalhos artesanais, incluindo a produção de cerveja. Isto se deu, principalmente, pelo fato dos monges dominarem a escrita, possibilitando o seu registro.

$\mathrm{Na}$ contemporaneidade, diante de uma produção profissionalizada, escolas de produção cervejeiras no mundo foram consolidadas: a Alemã, a Britânica, a Americana e a Belga. Segundo Morado (2017), a Escola Alemã está presente na grande região que abrange a Alemanha, República Tcheca (Boêmia), Eslováquia, Áustria, Holanda e Polônia. Toda essa região considera a cerveja como uma personagem central de sua 
história. A grande contribuição dessa escola cervejeira é o rigor técnico, a seriedade e o respeito devido à cerveja. Criaram regras e limites para produção promulgando a Reinheitsgebot no ano de 1.516, a Lei da Pureza da Cerveja (SCHLÜTER, 2003). Essa Lei determinava que a cerveja só pudesse ser feita a partir de água, malte de cevada e lúpulo, consequentemente, as cervejas dessa escola são caracterizadas pelo sabor menos amargo e mais maltado. Hoje, a Alemanha é o quarto maior produtor de cerveja do mundo, consumindo internamente $85 \%$ de toda a produção. O consumo per capita de cerveja no país é de mais de 100 litros por ano. Na região da Baviera, o consumo chega a 200 litros por ano (MORADO, 2017).

Ainda na Europa, diferentemente do que se imagina, escoceses e ingleses consomem mais cerveja do que uísque. A Escola Britânica de cervejas é composta pelo Reino Unido (Inglaterra, Escócia, País de Gales e Irlanda do Norte) e pela República da Irlanda, sendo representada por aproximadamente 1.400 cervejarias, que são capazes de empregar cerca de 20 mil pessoas diretamente, além de outras 300 mil, indiretamente (MORADO, 2017). Ainda conforme destaca o autor, uma informação interessante na cultura cervejeira britânica é a participação feminina na fabricação de cervejas. Em torno de $60 \%$ das pessoas empregadas são mulheres. Oliver (2012), por sua vez, destaca que do total de cervejas produzido na Inglaterra, 50\% é para consumo interno do país. Assim, a cultura cervejeira britânica se consolida na tradição dos famosos pubs, em especial nos londrinos.

Já em relação à Escola Americana, essa é reconhecida ou identificada nas cervejas mais amargas, maltadas, complexas e aromáticas, possuindo como destaque o uso de produtos locais (abóbora, aveia, lúpulos americanos, entre outros), seguida de total liberdade e criatividade para compor suas receitas (STACK, 2000).

Na Bélgica, a cultura cervejeira fez com que a bebida se tornasse Patrimônio Cultural Imaterial da Humanidade pela Organização das Nações Unidas para a Educação, a Ciência e a Cultura (UNESCO, 2016).

Muitos aficionados veem a Bélgica como a pátria da cerveja, especialmente porque essaherança de fabricação de cerveja remonta há muitos séculos, mas ainda fornece influência e ins piração para os cervejeiros modernos. A cerveja é parte do nosso DNA, e o significado histórico da nossa cultura da cerveja é até reconhecido pela UNESCO, que inscreveu a cultura da cerveja belga em sua lista do patrimônio cultural intangível da humanidade em 2016 (FLANDERS, 2019). 
Na Bélgica, o processo de fabricação de algumas cervejas sofisticadas segue qualificações típicas da fabricação do vinho, como Grand Cru, Réserve e Cuvée. Ainda cabe citar como exemplo a DeuSBrut Des Flandres, que é preparada pelo método champenoise, o qual surgiu a partir da submissão de uma cerveja Ale belga " a uma segunda fermentação na garrafa, seguindo a técnica tradicional de produção de champanhes" (MORADO, 2017, p. 152), ou seja, além de ser refermentada na garrafa, ela é submetida às etapas de remuage (rotações periódicas e inclinações progressivas) e dégorgement (congelamento do gargalo e retirada dos resíduos).

Outra característica referencial da cultura cervejeira belga é a tradição milenar das abadias, que são mosteiros (ou monastérios) onde residem comunidades cristãs, que dominam a escrita desde os tempos remotos. Algumas destas abadias fabricam a cerveja para consumo próprio e, em alguns casos, as comercializam, com o intuito de subsidiar as necessidades do mosteiro (MARQUES, 2019). Eles simbolizam uma época e dão exemplos de preservação da cultura cervejeira, justificando o fato de 6 dos 11 mosteiros que produzem cervejas trapistas no mundo estarem na Bélgica, que conta com mais de 20 abadias produtoras de cervejas (OLIVER, 2012).

Além de aspectos geográficos, as cervejas podem ter a diferenciação por tipo, sendo denominadas de acordo com aquelas já existentes e de reconhecimento mundial, conforme o Beer Judge Certification Program - BJCP (2019): Pilsen, Export, Lager, Dortmunder, Munchen, Bock, Malzbier, Ale, Stout, Porter, Weissbier, Alt e outras possíveis denominações que vierem a ser criadas, observadas as características do produto original. Atualmente, além destas que eram as inicialmente indicadas pela legislação, tem-se subclassificações de seus tipos, como por exemplo: American Lager, Premium, Helles, Schwarzbier, Doppelbock, MarzenLager, American Pale Ale, English IPA, Altbier, Weizen, Hefeweizen, Dunkelweizen, Weizenbock, Witibier, BerlienrWeisser, DryStout, American Stout, SweetStout, OatmealStout, Russian Imperial Stout, Lambic e agora tem-se a brasileira Catharina Sour.

No caso do Brasil, de acordo com Coutinho (2019), a cerveja tem seus primeiros registros no século XVII, tendo sido trazida por Maurício de Nassau a Recife, estado de Pernambuco. Dentre outros estudiosos da cerveja que vieram com Nassau, estava o cervejeiro holandês Dirck Dick, que montou a primeira cervejaria da história brasileira, 
em 1640, na própria casa de Nassau, na residência chamada "La Fontaine", onde fabricavam uma cerveja encorpada, com cevada e açúcar.

De acordo com Giorgi e Conceição Júnior (2016, p. 34) "segundo os 'cultos em cerveja' quando falamos nela, devemos ter em mente um alimento completo e complexo de importância ímpar, elemento cultural valorizado e de suma importância para diversas civilizações ao longo do processo histórico". Assim, em algumas cidades localizadas no Brasil, como Petrópolis e Blumenau, a cerveja é considerada um elemento identitário do lugar e de sua população e que faz parte das práticas e espaços de hospitalidade que se correlacionam ao turismo.

No município do Rio de Janeiro, em 2018, a Câmara de Vereadores, por meio de projeto de autoria dos vereadores Rafael Aloisio Freitas e Carlo Caiado, declarou a cerveja artesanal como patrimônio cultural, de natureza imaterial da cidade, por intermédio da Lei no 6.400/2018.

Estas e tantas outras cidades brasileiras adquiriram, ao longo do tempo, características e popularidade mediante a produção da cerveja. Mediante tal expertise, têm promovido eventos temáticos de diferentes magnitudes com o intuito de não apenas atrair um novo público, mas principalmente valorizar esta importante cultura no país.

\section{A HOSPITALIDADE, OS EVENTOS E OS HOTÉIS CERVEJEIROS}

A cerveja e a hospitalidade interagem, pois os espaços e práticas de hospitalidade podem ser cidades ou eventos que tenham a cerveja como principal elemento, correlacionando-a com a cultura local e equipamentos de hospitalidade, como restaurantes e hotéis em que a cerveja passa a figurar como elemento de atração e de customização de seus negócios.

Lashley (2015, p. 81) considera que "o fornecimento de alimentos, bebidas e hospedagem representa um ato de amizade: cria laços simbólicos, conectando pessoas que estabelecem vínculos, comprometendo os envolvidos com o compartilhamento da hospitalidade". É neste contexto que Camargo (2004, p. 19) considera que a hospitalidade pode ser definida como um "ato humano, exercido em contexto doméstico, público ou profissional, de recepcionar, hospedar, alimentar e entreter pessoas temporariamente deslocadas de seu hábitat".

Turismo e Sociedade (ISSN: 1983-5442). Curitiba, v. 12, n. 2, p. 110-129, maio-agosto de 2019. 
A partir dessa visão de Camargo (2004), temos a hospitalidade como situação que envolve diferentes práticas sociais, que podem ocorrer em variados espaços, como nos ambientes público, comercial e/ou doméstico, sejam eles urbanos ou rurais. Tal visão corrobora com o pressuposto de que a cultura cervejeira, como uma prática cultural, adentra os rituais da hospitalidade nos âmbitos social, privado, público e comercial.

Os eventos, por sua vez, são meios em que fica evidenciada essa interação cerveja e hospitalidade. Eles buscam conjugar a cultura étnica e oferecer uma experiência relacionada com a bebida, seja pela tradição histórica ou pela oportunidade de confraternização. Segundo Morado (2017, p. 96), “desde a revitalização da cultura da cerveja, na segunda metade do século $\mathrm{XX}$, surgem e prosperam pelo mundo festivais, concursos, festas, campeonatos... tudo vira um bom motivo para se reunir e beber cerveja".

No mundo, pode-se destacar como os principais eventos a American CraftBeer Week (nos Estados Unidos da América), o BelgianBeer Weekend (em Bruxelas, na Bélgica) e o Starkbierzeit (na Alemanha). No Brasil, o Festival Brasileiro de Cerveja (em Blumenau, Santa Catarina), IPA Day Brasil (em Ribeirão Preto, São Paulo) e o Mondial de La Bière (no Rio de Janeiro, no estado do Rio de Janeiro).

Ainda no Brasil, pode-se destacar no município de Petrópolis, no Estado do Rio de Janeiro, a Bauernfest, Festa do Colono Alemão, um festival que homenageia os imigrantes alemães anualmente, no mês de junho. A Bauernfest ocorre desde 1989 e é considerada a maior festa do município, bem como uma das maiores do Brasil, sendo que no ano de 2019, realizou-se a sua 30ª edição. No Quadro 1, a seguir, é possível visualizar o calendário de eventos cervejeiros no ano de 2019. 
QUADRO 1: CALENDÁRIO DE EVENTOS CERVEJEIROS NO BRASIL (2019)

\begin{tabular}{|c|c|c|c|}
\hline $\begin{array}{c}\text { Mês de } \\
\text { Realização }\end{array}$ & Nome do Evento & Cidade & Estado \\
\hline Janeiro & AllBeers Sessions 2019 & São Paulo & SP \\
\hline Fevereiro & BrewingFriends Festival 2019 & Rio de Janeiro & RJ \\
\hline Fevereiro & FloripaCraftBeer Festival 2019 - Edição Verão & Florianópolis & SC \\
\hline Março & Festival Brasileiro da Cerveja 2019 & Blumenau & SC \\
\hline Abril & Festa Confece 12 anos & Belo Horizonte & $\mathrm{MG}$ \\
\hline Maio/Junho & Mondial de La Bière SP 2019 & São Paulo & $\mathrm{SP}$ \\
\hline Junho & SlowBrew Ribeirão 2019 & Ribeirão Preto & SP \\
\hline Junho & Piri Bier 2019 & Pirenópolis & $\mathrm{SC}$ \\
\hline Junho & Blumenau International Beer Festival 2019 & Blumenau & SC \\
\hline Junho & $30^{\mathrm{a}}$ Bauernfest & Petrópolis & $\mathrm{RJ}$ \\
\hline Julho & Festival Nacional da Cerveja de Inverno - Winterbierfest & Treze Tílias & $\mathrm{SC}$ \\
\hline Julho & Festa de 4 anos da Dogma & São Paulo & SP \\
\hline Julho & DUM DAY 9 & Curitiba & PR \\
\hline Julho & Rio CraftBeer Festival 2019 & Rio de Janeiro & $\mathrm{RJ}$ \\
\hline Agosto & Invicta Nocaute Festival 2019 & Ribeirão Preto & SP \\
\hline Agosto & Festival Sul-Americano de Cerveja 2019 & Porto Alegre & $\mathrm{RS}$ \\
\hline Agosto & Ceva no Total 2019 & Porto Alegre & RS \\
\hline Agosto & Festival da Cultura Cervejeira Artesanal-FICC 2019 & Curitiba & PR \\
\hline Setembro & Mondial de La Bière Rio 2019 & Rio de Janeiro & RJ \\
\hline Setembro & IV Festival Amazônico de Cerveja & Belém & $\mathrm{PA}$ \\
\hline Setembro & HOPS FEST 2019 & Goiânia & GO \\
\hline Setembro & Festival Internacional de Cerveja e Cultura 2019 & Belo Horizonte & MG \\
\hline Outubro & Oktoberfest 2019 & Blumenau & $\mathrm{SC}$ \\
\hline Outubro & Lohn Open Haus & Lauro Müller & $\mathrm{SC}$ \\
\hline Outubro & Da Fazenda ao Copo 2019 & Paraisópolis & MG \\
\hline Outubro & Repense Cerveja 2019 & Rio de Janeiro & RJ \\
\hline Novembro & IPA Day Brasil 2019 & Ribeirão Preto & SP \\
\hline Novembro & Piri Bier Goiânia 2019 & Goiânia & GO \\
\hline Novembro & Festival da Cerveja POA 2019 & Porto Alegre & $\mathrm{RS}$ \\
\hline Dezembro & SlowBrew Brasil 2019 & São Paulo & SP \\
\hline Dezembro & Happy New Year 2020 & Rio de Janeiro & $\mathrm{RJ}$ \\
\hline
\end{tabular}

FONTE: Brewer Stage (2019), organizado pelos autores.

Pode-se perceber no Quadro 1 que a maioria dos eventos cervejeiros concentramse nas regiões sul e sudeste, com alguns eventos isolados nas regiões norte e centro-oeste. Por outro lado, observa-se que os principais eventos que celebram a bebida são realizados ao longo de todo o ano, propiciando a participação não apenas do público, mas também das empresas que trabalham, especificamente, na cadeia produtiva da cerveja, incluindo produção e serviços.

Especificamente em hotéis, pode-se destacar o Hotel Doghouse, no estado de Ohio, no Canal Winchester, nos Estados Unidos da América, da cervejaria Brewdog, sediada na Escócia. Este meio de hospedagem possui 32 Unidades Habitacionais (UH’s) que, além de serem equipados com geladeiras abastecidas com cervejas BrewDog, contam com torneiras de chope e, até mesmo, um minibar (geladeira de quarto) no 
banheiro privativo para que o hóspede possa consumir a cerveja enquanto toma seu banho (NEWSNER, 2018). Todas as unidades têm vista para a cervejaria, para que os hóspedes possam assistir os cervejeiros trabalhando. A cervejaria também investe em restaurantes e bares com a própria marca, tendo inaugurado um na cidade de São Paulo, Brasil.

Outra marca conceituada no ramo das cervejas que possui hotéis que levam seu nome é a Dogfish, com o Hotel The DogfishInn, com 16 UH's em Lewes, Delaware, que garante que foram feitos para amantes de cerveja. Mantendo-se fiel a moda Dogfish Head, o visitante encontrará uma abordagem inusitada ao estilo, qualidade e artesanato em cada uma das UH's (DOGFISHINN, 2019).

No Brasil, os amantes de cerveja podem usufruir de uma experiência inusitada no Treze Tílias Park Hotel, em Treze Tílias, Santa Catarina. O referido hotel proporciona aos seus hóspedes a possibilidade de tomar banho, literalmente, de cerveja em suas UH's. As banheiras possuem torneiras de onde jorram a cerveja oriunda da cervejaria local Linden Bier (TTPH, 2019).

No Estado de Minas Gerais, existe o Hotel Fazenda da Chácara, que proporciona aos seus hóspedes um tour pela fábrica de cerveja Loba, seguido de uma degustação dos seus 16 estilos de cerveja (CERVEJARIALOBA, 2019)

Assim, a produção de cervejas artesanais se alinha com a hospitalidade e, portanto, se constituem em uma alternativa estratégica para promover novas experiências em determinados empreendimentos e destinos. Como sua fabricação pode ser localmente, em pequenos espaços, envolvendo elementos que indicam identidade e coesão social, cultural e territorial de ruralidades instituídas no contexto dos hotéis fazenda nas seções seguintes apresentam-se algumas possibilidades de serviços relacionados à hospitalidade no ambiente rural tratando especificamente desse meio de hospedagem.

\section{A CERVEJA ARTESANAL E OS HOTÉIS FAZENDA}

O crescimento populacional e a urbanização da sociedade trazem consigo não apenas consequências ao modo de vida, mas também à saúde das populações.

O distanciamento entre sociedade e natureza, principalmente nos maiores aglomerados, contribui para acentuar o estresse gerado pelo modo de vida moderno e para produzir uma visão idealizada do campo, que seria o portador de uma vida mais simples, em contato com a natureza, e o repositor das energias despendidas (GERALDO, 2012, p. 14). 
Neste processo, causado pela rotina extenuante do trabalho, ressurge a busca por ambientes mais amigáveis, o que ressalta a necessidade do oferecimento de produtos e serviços turísticos relacionados às lidas rurais, assim como para as atividades de lazer e entretenimento. Assim, o turismo rural apresenta-se como uma alternativa para atender essa demanda, visto que a valorização do ambiente rural e da cultura local são alguns dos principais atrativos dessa segmentação turística (CELSO, 2008).

Outro benefício oriundo das atividades turísticas em ambientes rurais consiste na possibilidade de geração de emprego e renda para a sua população. Conforme observa Novaes (1994, p. 50), o "turismo rural vem beneficiando os moradores da área rural, próximo a cada fazenda, gerando novas fontes de renda a estas famílias, e contribuindo muito para evitar o êxodo rural".

No entanto, na lida do campo o turismo usualmente não é a única atividade. Como enfatiza Queiroz (2017, p. 448), as "atividades não agrícolas aparecem como opção de geração de renda, incentivando a permanência da população no meio rural, sobressaindose as relacionadas ao lazer e ao turismo". Ou seja, há uma diversificação e ampliação da oferta de produtos e serviços, agregando valor à vida e à cultura rural.

O incremento do turismo em espaços rurais auxilia a valorização do território. Não obstante, a criação de novas atividades laborais, associados ao uso maciço de mão de obra, oportuniza a permanência em seu habitat mediante a valorização do ambiente pelos turistas.

Deste modo, os destinos, assim como seus respectivos atrativos locais, devem possuir características específicas, valorizando a experiência não somente por estar em um ambiente rural, mas que possuem outros atributos, representados por serviços e produtos oriundos da própria região, quiçá do próprio empreendimento turístico:

observa-se que os elementos mais valorizados são os elementos espaciais como a natureza local, a partir da contemplação da paisagem; produção local, o que remete às funções tradicionais do rural; e a valorização dos produtos, consumidos em feiras na cidade e que são divulgados a partir de visitações ao roteiro (TEIXEIRA; SOUZA, 2012, p. 249).

Um exemplo de empreendimento com estas características são os meios de hospedagem conceituados como hotéis fazenda, tipo específico de empresa turística localizada em ambientes campesinos. Como Alves, Silva e Salazar (2017, p. 536) 
destacam, em algumas áreas rurais, "o hotel-fazenda pode ser o principal ou o único atrativo turístico existente na cidade, podendo ser ao mesmo tempo a motivação e a estrutura de apoio para os turistas que o procuram".

Os hotéis-fazenda se diferenciam dos demais tipos de meios de hospedagem por utilizarem o espaço rural como um dos recursos de maior atratividade (ALVES; SILVA; SALAZAR, 2017). Destarte, estes devem priorizar a aquisição ou produção local, buscando não apenas a originalidade e a ampliação da gama de produtos e serviços, mas também o aquecimento da economia local:

Diferentemente dos hotéis localizados em áreas urbanas, os hotéis -fazenda geralmente não trabalham com economia de escala, pois possuemum número reduzido de quartos e para alcançar uma boa lucratividade precisam explorar outros recursos, como por exemplo, a localização em um ambiente atrativo e agradável, que possibilite o contato mais próximo com a natureza e com o modo de viver do campo (ALVES; SILVA; SALAZAR, 2017, p. 547).

Nesse sentido, ressalta-se ainda mais a valorização das atividades agropecuárias desenvolvidas, das práticas e dos costumes intrínsecos à cultura da localidade, reconhecida por acolher, de forma diferenciada, os seus visitantes. Os alimentos e as bebidas locais, por sua vez, tangenciam os aspectos mencionados anteriormente e como Carvalho (2015, p.314) aponta "um símbolo bastante característico da hospitalidade rural é a oferta gastronômica de produtos caseiros e artesanais como doces, bolos, chás, café, biscoitos, sucos naturais, entre outros" (CARVALHO, 2015, p. 314).

Observa-se, portanto, que em empreendimentos localizados no espaço rural, como os hotéis fazenda, a gastronomia assume um papel importante na relação entre os turistas e a população local, especialmente nos casos em que os alimentos e bebidas refletem a cultura local. Nestes casos, estas relações tendem a valorizar as experiências dos turistas mediante o consumo de produtos originalmente regionais ou até mesmo únicos, exclusivos, fabricados de forma artesanal e inclusiva.

Aliado a valorização do lugar, o planejamento do turismo cultural e sua preocupação com a gastronomia, quando proposto com perspectivas sustentáveis e leva em consideração a participação ativa da comunidade local, atende a demanda de satisfazer ambos os envolvidos, ou seja, é possível criar um sistema de respeito e o interesse mútuo entre a população e os turistas (FERRO, 2013, p. 56).

E é neste cenário que surge a alternativa das cervejas artesanais. Conteúdo já abordado repetidamente. Conforme dados divulgados pelo Ministério da Agricultura, 
Pecuária e Abastecimento (MAPA) o número de cervejarias registradas no Brasil, em 2018, cresceu $23 \%$ em relação ao ano de 2017, sendo que foram registrados 6.800 produtos, entre cerveja e chope, mediante a abertura de 210 novas fábricas. Ou seja, em média, a cada dois dias, uma cervejaria abriu as portas no Brasil (BRASIL, 2019).

Esta expansão, capitaneada pela crescente produção das chamadas bebidas especiais, foi motivada principalmente pela mudança de perfil de consumo do brasileiro, que busca produtos diferentes, especialmente os regionais e locais, pois a cada dia, os consumidores destes produtos estão mais exigentes (BRASIL, 2019). Este cenário assume características mundiais, pois apesar das grandes multinacionais terem incorporado diversas empresas ao seu conglomerado, ampliando sua participação no mercado, há mudanças no comportamento e preferência dos consumidores, que tem buscado com maior avidez produtos artesanais e locais (SWINNEN, 2017).

Entretanto, não basta produzir bebidas de melhor qualidade e em maior quantidade. Faz-se necessário ter o domínio de todo o seu processo de produção até o momento do consumo pelos clientes. Em um ambiente rural, especialmente em hotéis fazenda, esta experiência deve valorizar as características do local, assim como do processo de fabricação da bebida. Afinal, é "evidente que a existência de cervejarias instaladas em destinos turísticos se configura como elemento/atrativo indispensável para fortalecer um destino que desenvolve atividades no turismo cervejeiro" (COELHOCOSTA, 2018, p. 350).

Na contemporaneidade, a cerveja é considerada como um elemento identitário do lugar e de sua população, que faz parte das práticas e espaços de hospitalidade que se correlacionam ao turismo. Ou seja, a cultura cervejeira, como uma prática cultural, adentra os rituais da hospitalidade nos âmbitos social, privado, público e comercial. Por isso eventos tradicionais e contemporâneos valorizam a bebida em todos os seus processos, assim como hotéis e restaurante investem na bebida como um diferencial de seu negócio. Logo, há uma oportunidade para a produção de cerveja artesanal integrar-se às atividades no espaço rural, como os hotéis fazendas, tema que será tratado na seção seguinte. 


\section{A PRODUÇÃO DE CERVEJA ARTESANAL NOS HOTÉIS FAZENDA}

Os hotéis fazenda, por essência, caracterizam-se pelas atividades produtivas, de lazer e gastronômicas, as quais denotam as possibilidades da produção de cerveja artesanal em suas instalações.

Embora a produção artesanal da cerveja necessite especificamente de uma estrutura adequada, com equipamentos, insumos, equipes, ela pode agregar valor aos serviços de alimentação, de bar e de entretenimento dos hotéis fazenda. Destaca-se ainda que o momento de consumo da cerveja artesanal, atrelado às estruturas já existentes, podem estimular esferas de hospitalidade e de maior permanência pelos hóspedes e/ou visitantes do empreendimento.

A produção de cervejas artesanais apresenta muitas possibilidades, desde pequenas instalações, mediante panelas específicas, como estruturas mais robustas, compostas por diferentes tanques, dutos e demais equipamentos, dependendo da necessidade de produção. É possível produzir cerveja em várias escalas, até mesmo para consumo próprio. Para produção comercial, além dos equipamentos, faz-se necessário atender às normas vigentes. Exemplos de estruturas e equipamentos, exigidos para diferentes formas de consumo e produção, são apresentados na Figura 1.

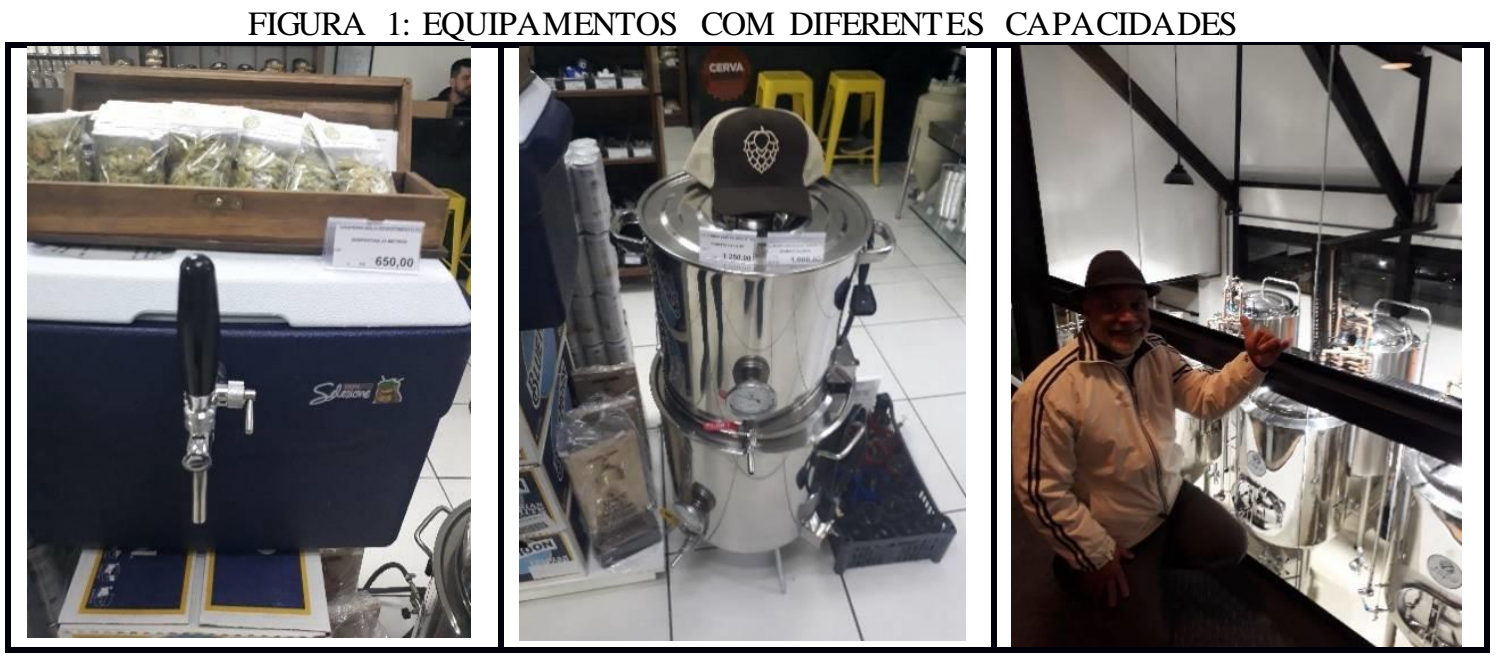

FONTE: Oliveira (2019).

As estruturas necessárias para cada empreendimento podem ser diversas, respeitando os objetivos de produção de cerveja estabelecidos pela administração dos hotéis fazenda. No caso de produção apenas interna, apenas para pequenos grupos, 
equipamentos simples são suficientes. Mas no caso do meio de hospedagem optar pela produção para abastecer o mercado local ou regional, a exigência de equipamentos e pessoal aumenta proporcionalmente.

Apesar de existirem diversas opções de tamanho e capacidade de produção, além das apresentadas na Figura 1, alternativas podem ser viáveis, destacando-se a brassagem em cervejarias ciganas. A brassagem consiste em uma mistura de grãos, no caso da cerveja artesanal, malte da cevada/trigo, com água aquecida, promovendo um líquido maltado denominado de mosto. A brassagem pode ser adquirida por intermédio de infusão ou decocção, isso vai variar conforme o desejo que se pretende com o produto.

Outra possibilidade de produção é a terceirização dos equipamentos, denominada popularmente como cervejaria cigana. Nesse caso os produtores de cervejas artesanais não precisam possuir seus próprios equipamentos, podendo produzir suas cervejas em locais que alugam os equipamentos necessários para a produção. Além disso, esses locais normalmente possuem o devido registro no Ministério de Agricultura e Pecuária (MAPA), facilitando a legalização para comercialização da cerveja (TORRENTE, 2019). É neste contexto que os hotéis fazenda podem cumprir o papel de centralizador deste processo, trazendo pessoas ou grupos para produzirem as suas cervejas no meio de hospedagem.

Outro ponto importante a ser abordado refere-se ao tipo ou tipos de cerveja artesanal a ser produzida para consumo de hóspedes e visitantes. Tendo em vista a variada tipologia de cervejas existentes, o meio de hospedagem deve optar pela produção de cervejas específicas, pensando no seu público-alvo. Desta forma, a produção regular deve ser limitada a alguns tipos. No caso de produção sob demanda, os tipos de cerveja serão definidos pelos interessados.

Assim, o consumo e valorização da produção de cerveja nos hotéis fazenda podem se dar de diferentes características:

- Consumo interno - a cerveja artesanal ser oferecida no cardápio do meio de hospedagem, podendo ser de forma exclusiva ou não;

- Eventos internos e externos - eventos previamente programados, atraindo um maior número de pessoas, especialmente em festas típicas ou datas comemorativas. Estes eventos podem ser próprios ou regionais; 
- Brassagem para grupos - eventos de menor magnitude, onde os hóspedes programam a brassagem a ser realizada no hotel fazenda, com o tipo de cerveja encomendado pelos interessados, aliado à disponibilidade dos equipamentos e hospedagem. Estes grupos podem variar de tamanho;

- Visitas guiadas - visita de hóspedes e visitantes interessados em conhecer o processo de fabricação da cerveja;

- Degustação - devem ser planejados e organizados pelo pessoal do meio de hospedagem, como o happy hour, por exemplo. Pode ser aberto ao público em geral ou limitado às pessoas que estão hospedadas e convidados;

- Personalização - cervejas e rótulos produzidos individualmente ou em grupo nas brassagens podem ser impressos com os nomes das pessoas que a produziram, ou do grupo, caso tenham algum nome específico;

- Cursos - os meios de hospedagem, valendo-se de seus equipamentos, local, infraestrutura e know-how, podem oferecer cursos de produção de cervejas para diversos tipos de clientes, sejam eles iniciantes ou não.

Estas são algumas das possibilidades de organização de eventos para valorizar a produção das cervejas artesanais. Há que se destacar que o processo de produção de cervejas artesanais não é instantâneo. O tempo de maturação varia de acordo com o tipo de cada cerveja. Desta forma, o acompanhamento deste processo requer uma para cada evento e as diversas etapas da produção, como seleção de ingredientes, a brassagem em si, o engarrafamento, a maturação, até chegar ao momento da degustação.

É importante, ainda, que se dê atenção não apenas ao processo de produção da cerveja, no qual se devem tomar todos os cuidados possíveis para se evitar defeitos de produção (off flavors) ou desperdícios. No entanto, uma etapa fundamental, mas que normalmente é relegada a um segundo plano relaciona-se ao serviço prestado aos clientes, destacando-se alguns procedimentos básicos, descritos a seguir:

- Utilizar copos adequados para cada tipo de cerveja;

- Lavar e secar os copos de forma correta;

- Conhecer a forma correta de servir os diferentes tipos de cerveja; 
- Dominar as informações sobre os diferentes tipos de cerveja para informar aos clientes;

- Indicar e oferecer opções de alimentos para harmonização com os diferentes tipos de cerveja;

- Proporcionar locais apropriados para a realização de cursos de produção;

- Estruturar brew-pubs para hóspedes e clientes consumirem a cerveja em ambientes propícios no hotel fazenda;

- Treinar o pessoal da região para prestar todos os serviços listados acima.

Logo, o processo de produção e consumo de cervejas artesanais podem não apenas otimizar a ocupação do meio de hospedagem, mas também valorizar a sua cultura e identidade.

\section{CONCLUSÃO}

Percebe-se que, cada vez mais, a cerveja, nas mais diversas culturas e nações, está relacionada ao ritual do acolhimento nas relações entre comunidade local, sua cultura e o visitante. Isso se evidencia pelos inúmeros eventos e espaços, cuja produção de cerveja e $\mathrm{o}$ ato de beber coletivamente essa iguaria, conjugam elementos fundamentais de hospitalidade em eventos, empresas, municípios e hotéis, que investem para a valorização de um já considerado bem imaterial dos lugares.

Nesse contexto os hotéis fazenda, com sua atmosfera rural, grandes espaços, destinados à recreação e lazer, podem se inserir, aumentando a sua lucratividade e valorizando ainda mais a cultura local e produtos artesanais. As diversas possibilidades de eventos, dependendo de cada meio de hospedagem, podem atrair novos hóspedes e visitantes, especialmente, em períodos de baixa temporada.

Outra vantagem competitiva dos meios de hospedagem, diferentemente de um evento, que apenas comercializa os produtos, concentra-se no fato de que todo o processo poderá ser devidamente acompanhado, não se limitando apenas à cadeia de produção, mas também ao ato de servir. 
Desta forma, pode-se destacar que os hotéis fazenda possuem os atributos necessários para produzir, de forma artesanal e personalizada, cervejas no ambiente rural, valorizando ainda mais os seus relevantes atrativos e atributos turísticos e culturais.

Soma-se a isto a propensão dos diversos atores, sejam eles empreendedores, turistas ou população local, em promover a atividade no local, o que possibilitará não apenas a sua valorização, mas até mesmo a criação futura de uma marca de qualidade para os produtos e serviços oferecidos no local. Mediante sua implementação, vislumbrase a possibilidade de ofertar produtos e serviços rurais de qualidade, ampliando as chances de melhoria da qualidade de vida da comunidade local.

$\mathrm{O}$ artigo se apresenta como uma reflexão inicial sobre a aproximação no campo teórico do tema da produção de cerveja artesanal ao contexto dos hotéis fazenda, demonstrando possibilidades e possíveis caminhos a serem adotados se a realidade do empreendimento se demonstrar como potencial e oportuna. Aponta-se, por fim, a necessidade de realizar estudos de casos específicos onde existem essas práticas para inferir seus impactos tanto na lógica de rendimentos e de custos, assim como sobre a dinâmica de produtos, inovações, perspectivas e aprendizados. Além disso, destaca-se a possibilidade de traçar paralelos entre a realidade brasileira e outros países produtores, especialmente, aqueles em que este importante mercado encontra-se em plena evolução.

\section{REFERÊNCIAS}

ALVES, L. O.; SILVA, L. A.; SALAZAR, V. S. Vantagem Competitiva no Turismo Rural - Análise dos Recursos Estratégicos de Hotéis Fazenda. Turismo em Análise, v. 28, n. 3, p.532-550, set./dez. 2017.

BELTRAMELLI, M. Cervejas, brejas e birras. 2a edição. São Paulo: Leya, 2014.

BRASIL. Ministério da Agricultura, Pecuária e Abastecimento. A cada dois dias uma cervejaria abre as portas no Brasil - Anuário da Cerveja. Disponível em: $<$ http//www.agricultura.gov.br/noticias/a-cada-dois-dias-uma-nova-cervejaria-abre-asportas-no-brasil>. Acesso em: 20 fev. 2019.

BREWER STAGE. Festivais e festas de cerveja para aproveitar em 2019 no Brasil. Disponível em: <https://brewerstage.com/pt/noticias/2019/01/festivais-festas-cervejapara-aproveitar-em-2019-no-brasil.html>. Acesso em: 20 jul. 2019.

CAMARGO, L. O. L. Hospitalidade. São Paulo: Aleph, 2004. 
CARVALHO, A. N. Hospitalidade Sob a Vertente Rural: uma reflexão acerca de sua reconstituição simbólica. Turismo em Análise, v. 26, n.2, p. 308-333, 2015.

CELSO, B. Turismo rural visto como um vetor de desenvolvimento local. In: ANAIS DO FÓRUM INTERNACIONAL DE TURISMO DO IGUASSU, 2, 2008, Foz do Iguaçu. Anais... Foz do Iguaçu, 2008.

CERVEJARIALOBA. Disponível em: <cervejarialoba.com.br> Acesso em: 10 dez. 2019.

COELHO-COSTA, E. R. Turismo cervejeiro no Brasil: uma realidade? Turismo e Sociedade, v. 11, n. 2, p.336-357, mai./ago. 2018.

COUTINHO, C. A. T. A Cerveja no Brasil de 1500 a 1799. Disponível em: $<$ https://www.cervesia.com.br/artigos-tecnicos/cerveja/his toria-da-cerveja/3-a-cervejano-brasil-de-1500-a-1799-seculo-xvii-a-xix.html>. Acesso em: 20 fev. 2019.

DOGFISHINN. Disponível em: < https://www.dogfish.com/inn>. Acesso em: 15 mar. 2019.

FERRO, R. C. Gastronomia e Turismo Cultural: reflexões sobre a cultura no processo do desenvolvimento local. Contextos da Alimentação - Revista de Comportamento, Cultura e Sociedade, v. 2, n. 2, p.38-56, 2013.

FLANDERS. Disponível em: <https://www.visitflanders.com/en/themes/belgian-beer/abrief-history-of-belgian-beer/index.jsp>. Acesso em: 20 jul. 2019.

GERALDO, J. C. Contribuição para a caracterização das atividades de turismo em espaço rural em propriedades de médio e grande porte nas cuestas do Estado de São Paulo. 190 f. Tese (Doutorado em Geografia) - Instituto de Geociências e Ciências Exatas, Universidade Estadual Paulista, Rio Claro, 2012.

GIORGI, V. V.; CONCEIÇÃO, J. O. A Produção Cervejeira Como Patrimônio Intangível. Cultura Histórica \& Patrimônio, v.3, n.2, p.140-164, 2016.

LASHLEY, C. Hospitalidade e hospitabilidade. Revista Hospitalidade. São Paulo, v. XII, n. especial, p. 70-92, 2015.

MARQUES, T. Abadia - O que significa isso quando falamos de cerveja? 2019. Disponível em: <http:/osboemios.com.br/cervejas/abadia/>. Acesso em: 10 dez. 2019.

MORADO, R. Larousse da cerveja. São Paulo: Alaúde, 2017.

NEWSNER. Disponível em: <https://br.newsner.com/ferias/inaugurado-o-primeirohotel-cervejaria-do-mundo-com-torneiras-de-chope-em-todos-os-quartos/>. Acesso em: 23 jul. 2019. 
NOVAES, M. H. Turismo rural em Santa Catarina. Turismo em Análise, v. 5, n. 2, p.43$50,1994$.

OLIVER, G. A mesa do mestre-cervejeiro: descobrindo prazeres das cervejas e das comidas verdadeiras. São Paulo: Editora Senac, 2012.

OLIVEIRA, S. D. Tipos de equipamentos para a produção de cerveja. 2019. 1 álbum, 27 fotografias, color, várias dimensões.

QUEIROZ, O. T. M. O rural como atrativo turístico e a experiência cultural: A Fazenda Santa Gertrudes. Rosa dos Ventos - Turismo e Hospitalidade, v. 9, n. 3, p. 447-456, jul./set. 2017.

SCHLÜTER, R.G. Gastronomia e Turismo. Tradução Roberto Sperling. São Paulo: Aleph, 2003.

STACK, M. Cervejarias locais e regionais na indústria cervejeira dos EUA, 1865-1920. Business History Review. 74. p.435-463, 2000.

SWINNEN, J. Beer Consumption and Trade in an Era of Economic Growth and Globalization. 2017. Disponível em: <http//www.choicesmagazine.org/choicesmagazine/theme-articles/beer-policy-and-a-changing-global- market/beer-consumptionand-trade-in-an-era-of-economic-growth-and-globalization>. Acesso em: 20 jun. 2019.

TEIXEIRA, A. R.; SOUZA, M. de S. A Valorização da Ruralidade a partir do Turismo: Roteiro Turístico Caminhos Rurais, Porto Alegre, Rio Grande do Sul, Brasil. Turismo e Sociedade, v. 5, n. 1, p. 231-251, 2012.

TORRENTE, A. O que são e como funcionam cervejarias ciganas. Disponível em: $<$ https://www.gazetadopovo.com.br/bomgourmet/o-que-sao-e-como-funcionamcervejarias-ciganas/>. Acesso em 24 jun. 2019.

TTPH: Treze Tilhas Park Hotel. Disponível em: <https:/ttph.com.br/: Acesso em 02 ago. 2019

SILVA, E. L.; MENEZES, E. M. Metodologia da pesquisa e elaboração de dissertação. $3^{\text {a }}$ edição. Florianópolis: Laboratório de Ensino à Distância da Universidade Federal de Santa Catarina, 2001.

UNESCO. Organização das Nações Unidas para a Educação, a Ciência e a Cultura. Unesco has listed belgiums beer culture among the intangibl. Disponível em: $<$ http://www. unesco.org/new/en/brussels/about-this-office/singleview/news/unesco_has_listed_belgiums_beer_culture_among_the_intangibl/>. Acesso em: 05 abr. 2019.

Recebido em: 31-07-2019.

Aprovado em: 19-12-2019.

Versão aprovada para publicação em: 28-01-2020 